\title{
Evaluation of haematological and behavioural changes in Channa punctatus (Bloch) on short-term exposure to a commercial-grade synthetic pyrethroid pesticide
}

\author{
Pratyush Ghosh*, Enakshi Das, Arka Ghosh
}

Department of Zoology, Chandernagore College, Chandannagar, Hooghly-712136, West Bengal, India

Received - December 03, 2021; Revision - January 05, 2022; Accepted - February 14, 2022

Available Online - February 28, 2022

DOI: http://dx.doi.org/10.18006/2022.10(1).97.103

KEYWORDS
Channa punctatus
$\mathrm{LC}_{50}$
Pesticide
Pyrethroid
Haematological
Behaviour

\begin{abstract}
This study aims to assess the acute toxicity of commercial-grade Cypermethrin (10\% EC) and evaluate the hematological and behavioral alterations in a freshwater fish Channa punctatus upon short-term exposure to Cypermethrin. A four-day static acute toxicity test was performed to estimate the median lethal concentration $\left(\mathrm{LC}_{50}\right)$ value of Cypermethrin. During the acute toxicity test, the behavior of the control and cypermethrin exposed fish was critically observed and recorded. After completing the acute toxicity test, the hematological effects of Cypermethrin in C. punctatus were evaluated using two sublethal dosages $(0.08 \mathrm{mg} / \mathrm{L}$ and $0.12 \mathrm{mg} / \mathrm{L})$. Results of the study revealed that this pesticide induced significant mortality in $C$. punctatus with a $96-\mathrm{h} \mathrm{L}_{50}$ value of $0.263 \mathrm{mg} / \mathrm{L}$. Cypermethrin exposed fish showed hyperactivity, irritability, erratic swimming, frequent surface visit, etc. Exposure to sublethal concentrations of Cypermethrin for a short period resulted in a significant decline $(\mathrm{P}<0.05)$ in total erythrocytes count (TEC), packed cell volume (PCV), mean corpuscular volume (MCV), and hemoglobin $(\mathrm{Hb})$ concentration as compared to control groups. In contrast, pesticide-exposed groups had a significant increase $(\mathrm{P}<0.05)$ in mean corpuscular hemoglobin concentration $(\mathrm{MCHC})$ and total leucocyte count (TLC). It is apparent from the results of the study that this commercial formulation is toxic to the studied fish. This study also revealed hematological and behavioral alterations in $C$. Punctatus which could be used as biomarkers for incipient Cypermethrin intoxication.
\end{abstract}

* Corresponding author

E-mail: pratyushghosh60@gmail.com (Pratyush Ghosh)

Peer review under responsibility of Journal of Experimental Biology and Agricultural Sciences.

Production and Hosting by Horizon Publisher India [HPI] (http://www.horizonpublisherindia.in/).

All rights reserved.
All the articles published by Journal of Experimental Biology and Agricultural Sciences are licensed under a Creative Commons Attribution-NonCommercial 4.0 International License Based on a work at www.jebas.org.

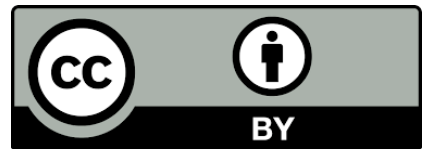




\section{Introduction}

Pyrethroids are synthesized from pyrethrins derived from Chrysanthemum cinerariifolium (Ullah et al. 2019). These are used as possible alternatives to some organochlorine, carbamates, and organophosphorus pesticides (Saxena and Seth 2002). Cypermethrin is a potent wide-spectrum synthetic Pyrethroid pesticide sold under the different trademarks (de Moraes et al. 2018; Sharma et al. 2021) and is extensively utilized against agricultural pests, household insects. Along with this, it is also used in fish farming as a chemotherapeutic to ectoparasites and biological vectors of fishes (de Moraes et al. 2018; Overton et al. 2019). In Indian natural waters, the level of Cypermethrin is found to be significantly higher than the acceptable threshold (Arisekar et al. 2019; Maurya et al. 2019; Sharma et al. 2021). The widespread use of pesticides in modern agriculture contributes to agricultural nonpoint source pollution. Pesticides are introduced into Indian natural water bodies through various natural processes such as surface run-off and soil erosion, posing a threat to drinking water resources as well as affecting a broad range of non-target phytoplankton, zooplankton, and higher trophic organisms such as fish and fish predators (Mondal et al. 2018; Rajmohan et al. 2020; Kalyabina et al. 2021). Cypermethrin is known to be toxic to aquatic organisms, especially to fish (de Moraes et al. 2018). Pyrethroids such as cypermethrin can readily permeate inside the gills, even at meager quantities in the water, rendering fish the most susceptible to the pesticide (Shaluei et al., 2012). As fish cannot adequately metabolize pyrethroids, their susceptibility to aqueous pyrethroid exposure is exacerbated (Borges et al. 2007).

By modulating the activities of many enzymes and metabolites, pesticide accumulation in tissue causes many physiological and biochemical changes in fish (Sarma et al. 2013). Pesticides alter the rate of enzymatic reactions and may also inhibit certain enzymes. Pesticide exposure in fish results in a considerable reduction in total protein levels, an increase in blood glucose levels, and significant alterations in total bilirubin, albumin, urea, inorganic phosphate, and cholesterol levels in serum. Pesticides also induce the production of reactive oxygen species (Ullah et al. 2019; Gonçalves et al. 2021). Blood serves as a pathophysiological indicator of the body since it is susceptible to both external and internal perturbations (Ismail et al. 2018). Assessments of hematological parameters might be effective for monitoring pesticide stress and can provide valuable information on the physiological responses of fish to changing environmental conditions (Agrahari et al. 2006).

The synthetic pyrethroid insecticide affects the central nervous system of fish through inhibition of acetylcholinesterase, which leads to hyperstimulation of nicotinic and muscarinic cholinergic receptors present the central nervous system. It ultimately causes a variety of behavioral inconsistencies (Borges et al. 2007; Ullah et al. 2019; Tsai and Lein 2021).
Though several authors reported the toxic impact of Cypermethrin on different fish species, still there is a paucity of scientific documentation on tropical freshwater fishes including Channa punctatus (Bloch) with combined biomarker approaches. $C$. punctatus also known as the spotted snakehead, is a tropical freshwater teleost found throughout the Indian subcontinent. These are the representatives of the Order Anabantiformes and are extremely valuable commercially. This species meets most of the requirements of a model species, including easy year-round availability and easy acclimatization under laboratory conditions. This study was aimed to investigate the acute toxicity of commercial-grade Cypermethrin and evaluate hematological and behavioral changes in $C$. punctatus upon short-term intoxication with Cypermethrin.

\section{Materials and Methods}

Healthy $C$. punctatus specimens (average length of $14.02 \pm 0.13$ $\mathrm{cm}$ and average weight of $42.34 \pm 1.71 \mathrm{~g}$ ) were obtained from local unpolluted water bodies. The fish specimens were acclimatized under laboratory conditions for seven days after collection. During this period, the fish were given a pelleted commercial fish meal once a day. The accumulated wastes were siphoned off daily. A commercial formulation of Cypermethrin $(10 \%$ EC) with the trade name Ustaad ${ }^{\mathrm{TM}}$, manufactured by United Phosphorus Limited (UPL), India, was used in this investigation, which was procured from the local market.

\subsection{Physico-chemical parameters of the diluent medium}

The temperature, $\mathrm{pH}$, and Total dissolved solids (TDS) were measured with the help of a portable instrument. Standard methods recommended by APHA (2012) were used for the estimation of dissolved oxygen (DO) and alkalinity. The mean and standard deviation (SD) of the water quality parameters are represented in Table 1.

Table1 Physico-chemical characteristics of the aqueous medium

\begin{tabular}{|cc|}
\hline Parameters & Value \\
\hline Alkalinity & $115.29 \pm 13.37 \mathrm{mg} / \mathrm{L}$ \\
\hline DO & $6.58 \pm 0.16 \mathrm{mg} / \mathrm{L}$ \\
\hline TDS & $690.35 \pm 38.71 \mathrm{mg} / \mathrm{L}$ \\
\hline pH & $7.3 \pm .01$ \\
\hline
\end{tabular}

\subsection{Acute toxicity bioassay}

Four days static acute toxicity test was performed to estimate the median lethal concentration $\left(\mathrm{LC}_{50}\right)$ value of Cypermethrin. Before determining the actual concentration of the test solution for the definitive test, a rough range-finding test was performed (Sarma et al. 2013; Ghosh et al. 2021). Under normal day/light conditions, a set of 10 randomly chosen fish specimens were subjected to 
different concentrations of the test chemical $(0.1,0.2,0.3,0.4,0.5$, $0.6, \& 0.7 \mathrm{mg} / \mathrm{L}$ ) in the definitive test. Frequent monitoring was made to observe the mortality of the fishes. The number of dead fishes was also recorded at the end of 24, 48, 72, 96 hours of exposure. As soon as feasible, the dead specimens were removed.

\subsection{Behavioural Observations}

The behavior of the control and cypermethrin exposed fishes was critically observed and recorded (qualitative analysis) during the acute toxicity test. Behavior of fish such as swimming pattern (normal/erratic), activity pattern (hypoactive/normal/hyperactive), the extent of mucous secretion (no mucous secretion/low mucous secretion/heavy mucous secretion), frequency of surface visit, etc. was taken into consideration for this study.

\subsection{Observations on Hematological Parameters}

Following the completion of the acute toxicity tests, the hematological effects of Cypermethrin were assessed using two sublethal dosages of $0.08 \mathrm{mg} / \mathrm{L}$ and $0.12 \mathrm{mg} / \mathrm{L}(30 \%$ and $45 \%$ of the 96-hour $\mathrm{LC}_{50}$ value, respectively). A pesticide-free control group was also prepared. Water was exchanged every 24 hours in the treatment sets to keep the concentration of Cypermethrin unchanged during the exposure period. Two sets were prepared, one of which was kept for up to 7 days and the other for 14 days. A pelleted fish meal was fed to the pesticide-exposed groups and the control group once daily. No mortality was reported during the experimentation periods. Fishes from each group were anesthetized on the 7th and 14th days before the blood was taken from them. Blood was collected by caudal puncture using $3 \mathrm{ml}$ sterile plastic syringes rinsed with an anticoagulant (1\% EDTA). Neubauer's Haemcytometer was used to determine the TEC (Total Erythrocyte Count) and TLC (Total Leukocyte Count) using RBC and WBC diluting fluid, respectively (Agrahari et al. 2006). The acidhematin method was used to calculate the concentration of hemoglobin (Hb) (Sood 2010). The microhematocrit method (Schalm et al. 1975) was used to determine Packed Cell Volume (PCV). Using standard formulas, mean corpuscular volume (MCV), mean corpuscular hemoglobin $(\mathrm{MCH})$, and mean corpuscular hemoglobin concentration (MCHC) were calculated (Dacie and Lewis 1991).

\subsection{Statistical Analysis}

$\mathrm{LC}_{50}$ values for $24,48,72$, and 96 hours were determined using Finney's Probit Analysis method with 95\% confidence limits, slope, and intercept values (Finney 1971). For hematological studies, the obtained values are presented as mean $\pm \mathrm{SD}$. One-way ANOVA was performed to discern the variance among groups. Dunnett's test was applied to establish comparisons between the control group and each of the treated groups. All the statistical analyses were performed using the Statistical package SPSS 21.0.

\section{Results}

Results of an acute toxicity test revealed that mortality in C.punctatus is proportional to the toxicant concentration. No mortality was observed in the control group during the experiment. The percentage of $C$. Punctatus mortality exposed to $0.0,0.1,0.2$, $0.3,0.4,0.5,0.6 \& 0.7 \mathrm{mg} / \mathrm{L}$ cypermethrin after 96 hours is presented in table 2 .

Table 2 Percentage mortality of $C$. punctatus after $96 \mathrm{~h}$ of exposure to Cypermethrin

\begin{tabular}{|c|cc|}
\hline Concentration & No. of alive fishes at 96 hours & \% of mortality at 96 hours \\
\hline 0 & 10 & NIL \\
\hline 0.1 & 10 & $30 \%$ \\
\hline 0.2 & 7 & $60 \%$ \\
\hline 0.3 & 4 & $80 \%$ \\
\hline 0.4 & 2 & $90 \%$ \\
\hline 0.5 & 1 & $100 \%$ \\
\hline 0.6 & 0 & $100 \%$ \\
\hline 0.7 & 0 & \\
\hline
\end{tabular}

Table $3 \mathrm{LC}_{50}$ Values of the Cypermethrin to C.punctatus at Different Exposure Period (with 95\% confidence limit, slope and intercept)

\begin{tabular}{|c|c|c|c|c|c|}
\hline \multirow{2}{*}{$\begin{array}{l}\text { Exposure Period } \\
\text { (hr) }\end{array}$} & \multirow{2}{*}{$\mathrm{LC}_{50} \mathrm{mg} / \mathrm{L}$} & \multicolumn{2}{|c|}{$95 \%$ confidence limit } & \multirow{2}{*}{ Slope \pm SE } & \multirow{2}{*}{ Intercept $\pm \mathrm{SE}$} \\
\hline & & Upper & Lower & & \\
\hline 24 & 0.40 & 0.34 & 0.46 & $7.30 \pm 4.53$ & $2.83 \pm 0.62$ \\
\hline 48 & 0.37 & 0.30 & 0.42 & $6.36 \pm 1.5$ & $2.95 \pm 0.62$ \\
\hline 72 & 0.32 & 0.27 & 0.38 & $6.52 \pm 1.39$ & $3.15 \pm 0.64$ \\
\hline 96 & 0.26 & 0.18 & 0.31 & $5.29 \pm 4.0$ & $3.07 \pm 0.67$ \\
\hline
\end{tabular}

Journal of Experimental Biology and Agricultural Sciences http://www.jebas.org 
Based on Probit analysis, the $\mathrm{LC}_{50}$ values of Cypermethrin for C.punctatus after 24, 48, 72, and 96 hours were $0.409,0.371$, 0.328 , and $0.263 \mathrm{mg} / \mathrm{L}$, respectively. As the span of exposure increased, the slope function decreased. Table 3 shows all the median lethal concentration $\left(\mathrm{LC}_{50}\right)$ values (with $95 \%$ confidence limits) for different exposure periods.

Throughout the study period, the fish in the control group appeared to be active and healthy. Fishes kept in lower concentrations of cypermethrin $(0.1 \mathrm{mg} / \mathrm{L}$ and $0.2 \mathrm{mg} / \mathrm{L})$ showed behavior similar to the control group. Hyperactivity and irritability continued for the first 24 hours of exposure at higher concentrations $(>0.2 \mathrm{mg} / \mathrm{L})$; thereafter, gradually slowed down. Erratic swimming behavior increased with the increasing concentrations and exposure time. The frequency of surface visits of fish exposed to Cypermethrin increased as the toxicant's concentration increased (Surface visits were observed to be more frequent at $0.6 \mathrm{mg} / \mathrm{L}$ and $0.7 \mathrm{mg} / \mathrm{L}$ ). However, at each concentration, as exposure time progressed, the frequency of surface visits reduced progressively. In the treated groups, there was a substantial rise in opercular activity. When comparing the treatment and control groups, it was found that opercular activity reduced steadily over time in the treated groups. Heavy mucus secretion, gulping of air, convulsions, and loss of equilibrium was evident before death. During the experiment, it was typical to see animals lying motionless at the bottom of the aquarium for extended periods.

In the present study, exposure of fish to two sub-lethal concentrations $(0.08 \mathrm{mg} / \mathrm{L}$ and $0.12 \mathrm{mg} / \mathrm{L})$ of Cypermethrin caused significant alterations in the haematological parameters of $C$. punctatus. The changes in control and cypermethrin-treated groups are presented in Table 4. One way ANOVA revealed that there was a statistically significant difference in TEC $[F(2,27)=134.34$, $\mathrm{P}<0.05], \mathrm{Hb}[\mathrm{F}(2,27)=75.83, \mathrm{P}<0.05], \& \mathrm{TLC}[\mathrm{F}(2,27)=212.43$, $\mathrm{P}<0.05$ ] between at least two sets. Further, statically significant difference was also evident in case of other hematological parameters like PCV $[\mathrm{F}(2,27)=1181.87, \mathrm{P}<0.05], \operatorname{MCV}[\mathrm{F}(2,27)$ $=385.04, \mathrm{P}<0.05], \mathrm{MCH}[\mathrm{F}(2,27)=9.44, \mathrm{P}<0.05], \& \mathrm{MCHC}[\mathrm{F}$ $(2,27)=107.94, \mathrm{P}<0.05]$.

Dunnett's test found that the mean value of TEC, PCV, MCV \& $\mathrm{Hb}$ decreased significantly $(\mathrm{P}<0.05)$ as compared to control. After clearing Levene's test for homogeneity in variance, Student's t-test revealed that hematological changes are not statistically significant between exposure tenure.

\section{Discussion and Conclusions}

Synthetic pyrethroids are used indiscriminately, which has various unforeseeable implications for non-target organisms. This study has evaluated the acute toxicity and hematological and behavioral changes in $C$. punctatus exposed to sublethal concentrations of commercial-grade cypermethrin for a short period.

The results of the present study showed that Cypermethrin induced significant mortality in C. punctatus with a $96 \mathrm{~h} \mathrm{~L}_{50}$ value of 0.263 $\mathrm{mg} / \mathrm{L}$. Borges et al. (2007) and Das and Mukherjee (2003) reported that the 96 hours $\mathrm{LC}_{50}$ value of Cypermethrin in Rhamdia quelen and Labeo rohita was $0.193 \mathrm{mg} / \mathrm{L}$ and $0.139 \mathrm{mg} / \mathrm{L}$,

Table 4 Hematological parameters of C.punctatus exposed to two $(0.08 \mathrm{mg} / \mathrm{L} \& 0.12 \mathrm{mg} / \mathrm{L})$ sublethal concentrations of Cypermethrin

\begin{tabular}{|c|c|c|c|c|}
\hline Parameter & Days of Exposure & Control & $0.08 \mathrm{mg} / \mathrm{L}$ Concentration & $0.12 \mathrm{mg} / \mathrm{L}$ Concentration \\
\hline \multirow[b]{2}{*}{$\operatorname{TEC}\left(\times 10^{6} \mathrm{~mm}^{-3}\right)$} & 7 & $3.16 \pm 0.05$ & $2.91 \pm 0.06$ & $2.71 \pm 0.04$ \\
\hline & 14 & $3.09 \pm 0.02$ & $2.8 \pm 0.02$ & $2.6 \pm 0.03$ \\
\hline \multirow[b]{2}{*}{$\mathrm{Hb}(\mathrm{gm} / \mathrm{dL})$} & 7 & $11.47 \pm 0.4$ & $10.68 \pm 0.32$ & $9.53 \pm 0.09$ \\
\hline & 14 & $10.85 \pm 0.25$ & $10.7 \pm 0.35$ & $9.29 \pm 0.06$ \\
\hline \multirow[b]{2}{*}{$\operatorname{PCV}(\%)$} & 7 & $34.53 \pm 0.4$ & $29.84 \pm 0.07$ & $24.22 \pm 0.12$ \\
\hline & 14 & $34.24 \pm 0.32$ & $28.91 \pm 0.09$ & $23.26 \pm 0.41$ \\
\hline \multirow[b]{2}{*}{$\operatorname{MCV}\left(10^{-4} \mathrm{fL}\right)$} & 7 & $109.45 \pm 2.85$ & $102.64 \pm 2.03$ & $89.27 \pm 1.32$ \\
\hline & 14 & $110.96 \pm 1.37$ & $103.12 \pm 1.06$ & $89.34 \pm 1.06$ \\
\hline \multirow[b]{2}{*}{$\mathrm{MCH}\left(10^{5} \mathrm{pg}\right)$} & 7 & $36.82 \pm 0.83$ & $36.77 \pm 1.7$ & $35.11 \pm 0.51$ \\
\hline & 14 & $35.17 \pm 0.77$ & $38.17 \pm 1.39$ & $35.69 \pm 0.39$ \\
\hline \multirow[b]{2}{*}{$\mathrm{MCHC}(\mathrm{g} \%)$} & 7 & $33.21 \pm 1.33$ & $35.81 \pm 1.09$ & $39.33 \pm 0.48$ \\
\hline & 14 & $31.7 \pm 0.7$ & $37.01 \pm 1.14$ & $39.45 \pm 0.78$ \\
\hline \multirow[b]{2}{*}{$\operatorname{TLC}\left(10^{3} \mathrm{~mm}^{-3}\right)$} & 7 & $17.84 \pm 0.6$ & $19.88 \pm 0.53$ & $20.89 \pm 0.05$ \\
\hline & 14 & $17.62 \pm 0.1$ & $20.29 \pm 0.52$ & $21.07 \pm 0.11$ \\
\hline
\end{tabular}

Journal of Experimental Biology and Agricultural Sciences http://www.jebas.org 
Table $5 \mathrm{LC}_{50}$ of Cypermethrin in various fish species

\begin{tabular}{|ccc|}
\hline Fish Species & LC $_{50} \mathrm{value}(\mathrm{Hour})$ & Reference \\
\hline Rhamdia quelen & $0.193 \mathrm{mg} / \mathrm{L}(96 \mathrm{~h})$ & Borges et al. (2007) \\
\hline Labeo rohita & $0.139 \mathrm{mg} / \mathrm{L}(96 \mathrm{~h})$ & Das \&Mukherjee (2003) \\
\hline Catla catla & $4.43 \mu \mathrm{g} / \mathrm{L}(96 \mathrm{~h})$ & Vani et al. (2012) \\
\hline Tor putitora & $63 \mu \mathrm{g} / \mathrm{L}(96 \mathrm{~h})$ & Vllah et al. (2015) \\
\hline Cirrhinus mrigala & $150 \mu \mathrm{g} / \mathrm{L}(96 \mathrm{~h})$ & Kumar et al. $(2007)$ \\
\hline Channa punctatus $(2012)$ \\
\hline Danio rerio & $0.4 \mathrm{mg} / \mathrm{L}(96 \mathrm{~h})$ & Xu et al. (2010) \\
\hline Channa punctatus & $0.27 \mathrm{mg} / \mathrm{L}(72 \mathrm{~h})$ & This study \\
\hline
\end{tabular}

respectively. On the other hand, Xu et al. (2010) and Kumar et al. (2007) obtained a relatively higher $\mathrm{LC}_{50}$ value in Danio rerio and C.punctatus as compared to this study (Table 5). The toxicity of Cypermethrin varies with fish species (Borges et al. 2007). Pyrethroid toxicity is incredibly reliant on the stoichiometry of the compound. Toxicity variations between formulations with the same ingredients may be influenced by the carriers, inert substances, physiology, sex of the test specimens, and the physiochemical properties of the aqueous media (Kumar et al. 2007; Sarma et al. 2013; Ghosh et al. 2021).

Stress-induced behavioral alterations are the most sensitive indicators of pesticide toxicity (Nwani et al. 2013). Exposure to Cypermethrin has resulted in behavioral changes in C.punctatus, among the reported behavior changes, irregular or erratic swimming, frequent surface visit, sinking to the bottom, and dyspnea are the most common ones. These findings were consistent with the findings of Polat et al. (2002), in Poecilia reticulata, Kumar et al. (2007), in C.punctatus, and Borges et al. (2007) in Rhamdia quelen. Synthetic pyrethroids put on hazardous effects on the nervous system of fish by altering the permeability of sodium channels and other voltage-gated channels like calcium and chlorine gated channels (de Moraes et al. 2018; Soderlund 2011; Ullah et al. 2019). Disturbances to these channels lead to different neurobehavioral changes, including hyperirritability (de Moraes et al. 2018). The acetylcholinesterase enzyme is active at both neuronal and neuromuscular junctions. Different behavioral inconsistencies can be attributed to acetylcholinesterase inhibition by the pesticide at the neuromuscular junction, culminating in impeded neural transmission and aggravated acetylcholine at nerve endings (Singh et al. 2018; Ullah et al. 2019).

In this study, C.punctatus exposed to sublethal concentrations of Cypermethrin showed a significant decrease $(\mathrm{P}<0.05)$ in TEC, $\mathrm{Hb}$, MCV. Similar observations were reported in Catla catla by Vani et al. (2012), in Alburnus tarichi by Özok et al. (2018), and in Anabas testudineus by Velmurugan et al. (2016). The findings of this study are also in agreement with the findings of Saxena and Seth (2002) in the same species. Further, Jayaprakash and Shettu (2013) reported a significant decrease in the $\mathrm{Hb}$ content, TEC, and $\mathrm{PCV}$ in $C$. punctatus exposed to another pyrethroid pesticide, deltamethrin. Borges et al. (2007) and Montanha et al. (2014) observed an increase in $\mathrm{Hb}$ content, whereas Das and Mukherjee (2003) reported a reduction in $\mathrm{Hb}$ content with no associated change in TEC due to Cypermethrin exposure. Anemia is generally thought to be caused by a decrease in hemoglobin and TEC levels (Saleh and Marie 2016). Inhibition of erythropoiesis is most likely the cause of anemia. Furthermore, due to a drop in $\mathrm{RBC}$ and $\mathrm{Hb}$, the oxygen-carrying capacity of blood in pesticide-exposed fish decreases (Adhikari et al. 2004). In this study, significant elevation in leukocyte count was observed, consistent with the findings of Velmurugan et al. (2016) in Anabas testudineus and with Adhikari et al. (2004) in Labeo rohita. This substantial increment could be ascribed to general immune response and defense against Cypermethrin (Khan et al. 2018). It is difficult to perform a meaningful comparative evaluation of the effect of Cypermethrin on the hematological profile of fish because of the variability of concentrations used, the period of exposure, and the fish species.

This study unraveled that despite low, sub-lethal and short-term exposure, the xenobiotic (commercial formulation of Cypermethrin) was able to elicit hematological adjustments and behavioral changes in C.punctatus. Hematological and behavioral alterations in C.punctatus could be used as biomarkers for incipient Cypermethrin intoxication. It was also evident that this species is more resistant to Cypermethrin's effects compared to other fish species. The changes reported here can be reflected in other parameters related to growth, reproduction, etc. which need to be investigated in future studies.

\section{Conflict of Interest}

The authors declare no potential conflict of interest. 


\section{References}

Adhikari, S., Sarkar, B., Chatterjee, A., Mahapatra,C.T., \& Ayyappan, S. (2004). Effects of cypermethrin and carbofuran on certain hematological parameters and prediction of their recovery in a freshwater teleost, Labeo rohita (Hamilton). Ecotoxicology and Environmental Safety, 58(2), 220-226.

Agrahari, S., Pandey, K.C., \& Gopal, K. (2006). Effect of monocrotophos on erythropoietic activity and hematological parameters of the freshwater fish Channa punctatus (Bloch). Bulletin of Environmental Contamination and Toxicology, 76(4), 607-613.

APHA (2012) Standard Methods for the Examination of Water and Wastewater.American Public Health Association, American Water Works Association and Water Environment Federation,Washington DC.

Arisekar, U., Shakila, R.J., Jeyasekaran, G., Shalini, R., et al. (2019). Accumulation of organochlorine and pyrethroid pesticide residues in fish, water, and sediments in the Thamirabarani river system of southern peninsular India. Environmental Nanotechnology, Monitoring and Management, 11, 100194.

Borges, A., Scotti, L.V., Siqueira, D.R., Zanini, R., et al. (2007). Changes in hematological and serum biochemical values in jundiá Rhamdia quelen due to sub-lethal toxicity of cypermethrin. Chemosphere, 69(6), 920-926.

Dacie,J.V.,\&Lewis, S.M. (1991). Practical haematology.Edinburgh: Churchill Livingstone.

Das, B.K., \& Mukherjee, S.C. (2003). Toxicity of cypermethrin in Labeo rohita fingerlings: Biochemical, enzymatic and haematological consequences.Comparative Biochemistry and Physiology - C Toxicology and Pharmacology, 134(1), 109-121.

de Moraes, F.D., Venturini, F.P., Rossi, P.A., Avilez, I.M., et al. (2018). Assessment of biomarkers in the neotropical fish Brycon amazonicus exposed to cypermethrin-based insecticide. Ecotoxicology, 27(2), 188-197.

Finney, D.J. (1971). Probit Analysis. London :Cambridge University Press.

Ghosh, P., Dutta, M., \& Panigrahi, A.K. (2021). Behavioral Biomarker Responses of Filopaludina bengalensis to Acute Copper Toxicity. Current World Environment, 16(1), 227-235.

Gonçalves, A. M. M., Rocha, C. P., Marques, J. C., \& Gonçalves, F. J. M. (2021). Enzymes as useful biomarkers to assess the response of freshwater communities to pesticide exposure - A review. Ecological Indicators, 122, 107303.
Ismail, M., Ali, R., Shahid, M., Khan, M.A., et al. (2018). Genotoxic and hematological effects of chlorpyrifos exposure on freshwater fish Labeo rohita. Drug and Chemical Toxicology, $41(1), 22-26$

Jayaprakash, C., \& Shettu, N. (2013). Changes in the hematology of the freshwater fish, Channa punctatus (Bloch) exposed to the toxicity of deltamethrin. Journal of Chemical and Pharmaceutical Research, 5(6), 178-183

Kalyabina, V. P., Esimbekova, E. N., Kopylova, K. V., \& Kratasyuk, V. A. (2021). Pesticides: formulants, distribution pathways and effects on human health - a review. Toxicology Reports, 8, 1179-1192.

Khan, N., Ahmad, M.S., Tabassam, S., Nouroz, F., et al. (2018). Effects of sub-lethal concentration of cypermethrin on histopathological and hematological profile of rohu (Labeo rohita) during acute toxicity. International Journal of Agriculture and Biology, 20 (3), 601-608.

Kumar, A., Sharma, B., \& Pandey, R.S. (2007). Preliminary evaluation of the acute toxicity of cypermethrin and $\lambda$-cyhalothrin to Channa Punctatus. Bulletin of Environmental Contamination and Toxicology, 79(6), 613-616.

Maurya, P.K., Malik, D.S., \& Sharma, A. (2019). Impacts of pesticide application on aquatic environments and fish diversity. In Kumar V, Kumar R, Singh J, Kumar P (Ed), Contaminants in Agriculture and Environment: Health Risks and Remediation (pp. 111-128). Haridwar, India: Agro Environ Media- Agriculture and Ennvironmental Science Academy.

Mondal, R., Mukherjee, A., Biswas, S., \& Kole, R. K. (2018). GCMS/MS determination and ecological risk assessment of pesticides in aquatic system: A case study in Hooghly River basin in West Bengal, India. Chemosphere, 206, 217-230.

Montanha, F.P., Fredianelli, A.C., Wagner, R., Sacco, S.R., et al. (2014). Clinical, biochemical and haemathological effects in Rhamdia quelen exposed to cypermethrin. Arquivo Brasileiro de Medicina Veterinaria e Zootecnia, 66(3), 697-704.

Nwani, C.D., Ivoke, N., Ugwu, D.O., Atama, C., et al. (2013). Investigation on acute toxicity and behavioral changes in a freshwater African catfish, Clarias gariepinus (Burchell, 1822), exposed to organophosphorous pesticide, Termifos®. Pakistan Journal of Zoology, 45(4), 959-965.

Overton, K., Dempster, T., Oppedal, F., Kristiansen, T.S., et al. (2019). Salmon lice treatments and salmon mortality in Norwegian aquaculture: a review. Reviews in Aquaculture, 11(4), 1398-1417. 
Özok, N., OĞuz, A.R., Kankaya, E., \& Yeltekin, A.Ç. (2018). Hemato-biochemical responses of Van fish (Alburnus tarichi Guldenstadt, 1814) during sublethal exposure to cypermethrin. Human and Ecological Risk Assessment, 24(8), 2240-2246.

Polat, H., Erkoc, F.U., Viran, R., \& Kocak, O. (2002) Investigation of acute toxicity of beta-cypermethrin on guppies Poecilia reticulata. Chemosphere, 49, 39-44.

Rajmohan, K. S., Chandrasekaran, R., \& Varjani, S. (2020). A review on occurrence of pesticides in environment and current technologies for their remediation and management. Indian Journal of Microbiology, 60(2), 125-138.

Saleh,Y.S., \& Marie, M.A.S. (2016). Use of Arius thalassinus fish in a pollution biomonitoring study, applying combined oxidative stress, hematology, biochemical and histopathological biomarkers: A baseline field study. Marine Pollution Bulletin, 106 (1-2), 308322.

Sarma, D., Das, J., \& Dutta, A. (2013). Acute toxicity and behavioural changes in Channa punctatus (Bloch) exposed to Rogor (an organophosphorus pesticide). Nature Environment and Pollution Technology, 12(4), 641-644.

Saxena, K.K., \& Seth, N. (2002). Toxic effects of cypermethrin on certain hematological aspects of fresh water fish Channa punctatus. Bulletin of Environmental Contamination and Toxicology,69(3), 364-369.

Schalm, O. W., Jain, N. C., \& Caroll, E. J. (1975). Veterinary haematology 3(Ed). Philadelphia,USA: Lea and Fibiger.

Shaluei, F., Hedayati, A., Kolangi, H., Jahanbakhshi, A., \& Baghfalaki, M. (2012). Evaluation of the acute toxicity of cypermethrin and its effect on behavioral responses of Caspian Roach (Rutilus rutilus caspicus) and silver carp (Hypophthalmicthys molitrix). Global Veterinaria, 9(2), 215-219.

Sharma, R., Jindal, R., \& Faggio, C. (2021). Cassia fistula ameliorates chronic toxicity of cypermethrin in Catla catla. Comparative Biochemistry and Physiology Part-C:Toxicology and Pharmacology, 248, 109113.
Singh, S., Tiwari, R.K., \& Pandey, R.S. (2018). Evaluation of acute toxicity of triazophos and deltamethrin and their inhibitory effect on AChE activity in Channa punctatus. Toxicology Reports, $5,85-89$

Soderlund, D.M. (2011). Molecular mechanisms of pyrethroid insecticide neurotoxicity: recent advances. Archives of Toxicology, 86(2), 165-181.

Sood, R. (2010). Hematology for Students and Practitioners. New Delhi : Jaypee Brothers Medical Publishers (P) Ltd..

Tsai, Y.H., \& Lein, P. J. (2021). Mechanisms of organophosphate neurotoxicity. Current Opinion in Toxicology, 26, 49-60.

Ullah, R., Zuberi, A., Naeem, M., \& Ullah, S. (2015). Toxicity to Hematology and Morphology of Liver, Brain and Gills during Acute Exposure of Mahseer (Tor putitora) to Cypermethrin. International Journal of Agriculture and Biology, 17, 199-204.

Ullah, S., Li, Z., Zuberi, A., Arifeen, M.Z.U., \& Baig, M.M.F.A. (2019). Biomarkers of pyrethroid toxicity in fish. Environmental Chemistry Letters, 17(2), 945-973.

Vani, T., Saharan, N., Roy, S.D., Ranjan, R., et al. (2012). Alteration in haematological and biochemical parameters of Catla catla exposed to sub-lethal concentration of cypermethrin. Fish Physiology and Biochemistry, 38(6), 1577-1584.

Vasantharaja,C., Pugazhendy, K., Venkatesan, S., et al. (2012). Acute Toxicity of Cypermethrin and its Impact on Biochemical Alteration in the Fresh Water Fish Cirrhinus mrigala (Hamilton) and Protective Effect of Cardiospermum helicacabum (Linn). International Journal of Pharmaceutical \& Biological Archives, 3(1), 146-152.

Velmurugan, B., Cengiz, E.I., Senthilkumaar, P., et al. (2016). Hematological Parameters of Freshwater Fish Anabas testudineus after Sublethal Exposure to Cypermethrin. Environmental Pollution and Protection, 1(1), 32-39.

Xu, C., Tu, W., Lou, C., Hong, Y., \& Zhao, M. (2010). Enantioselective separation and zebrafish embryo toxicity of insecticide beta-cypermethrin. Journal of Environmental Sciences (China), 22(5), 738-743. 